【研究简报】

\title{
生物圈二号内生长在很高 $\mathrm{CO}_{2}$ 浓度下的 几种植物光合能力的变化
}

\author{
蒋高明 (1) 林光辉 (2) \\ (1)中国科学院植物研究所, 北京 100093; (2)Biosphere 2 Education and Research Center, \\ Columbia University, PO Box 689, Oracle, AR 85623, USA)
}

\section{关链词光合作用 光补償点和光饱和点 衰现光能利用效率 $\mathrm{CO}_{2}$ 生物圈二号}

植物对 $\mathrm{CO}_{2}$ 浓度升高的响应表现在短期反应 ${ }^{[1]}$ 和长期适应 ${ }^{[2]}$ 两个方面. 在短期反应方 面: (1) 光合作用起初随 $\mathrm{CO}_{2}$ 浓度升高而得到促进; (2) 但随时间的延长表现为光合强度下 降. 这种现象主要与实验控制条件如光照、水分、养分及植物的生长空间受限有关 ${ }^{[3]}$. 因而 在对全球变化引起的植物适应研究方面, 进行长期反应即适应 (Acclimation) 实验研究更有意 义. 但目前所进行的有关研究 ${ }^{[4 \sim 6]}$, 植物生长的空间仍很小, 且对幼苗处理为主, 不能进行较 大植株 (尤其是高大树木) 的实验. 生物圈二号建于 1991 年, 占地面积 $1.28 \mathrm{hm}^{2}$, 植物生长空 间 $12.9 \times 10^{14} \mathrm{~m}^{3}$. 原设计目的是为今后太空探险作准备, 试图寻找适应人类生存的人工生态 系统. 但住人封闭实验后, $\mathrm{CO}_{2}$ 浓度升高很快. 1991 年 6 月为 $500 \mu \mathrm{mol} \cdot \mathrm{mol}^{-1}$, 到 1992 年 2 月即达到 $2500 \mu \mathrm{mol} \cdot \mathrm{mol}^{-1}$; 1993 年 2 月升至 $4000 \mu \mathrm{mol} \cdot \mathrm{mol}^{-1}$; 以后 $\mathrm{CO}_{2}$ 浓度维持在 1000 (夏季) $\sim 4000 \mu \mathrm{mol} \cdot \mathrm{mol}^{-1}$ (春季)之间. 封闭实验 2.5 年后即不再继续住人实验. 但是,生 物圈二号却提供了世界上独一无二的全球变化研究的理想场所. 里面的植物生长在很高的 $\mathrm{CO}_{2}$ 浓度里 (平均 $>2200 \mu \mathrm{mol} \cdot \mathrm{mol}^{-1}$ ) 约 4.5 年, 且大多从种子或幼苗开始生长. 生物圈二 号内有热带雨林、沙漠、萨王纳群落、红树林、海洋、农田等多种类型的生态系统, 约 1000 种植 物, 植物的生长空间不受限制. 本文对其中的植物进行不同 $\mathrm{CO}_{2}$ 浓度下光合作用测定, 首次 报道有关研究结果. 旨在揭示植物在高 $\mathrm{CO}_{2}$ 浓度下光合作用能力及其机制的改变, 深入探讨 $\mathrm{CO}_{2}$ 浓度升高对植物的直接影响.

2 Symons R. Self-cleavage of RNA in the replicative of small pathogens of plants and animals. TIBS, 1989, 14: 445 448

3 高振强, 高志萍, 刘喜富. 逆转病毒介导的 MDR1 反应 RNA 对人肺癌耐药性的逆转作用. 科学通报, 1996, 41(23): 1996

4 高振强, 高志萍. 肺癌细胞中 MDRI 基因的 PCR 定量分析, 见: 䓪林浩主编. 基础医学研究. 北京: 中国人事出版社, 1995. $574 \sim 578$

5 Kobayashi H, Dorai T, Holland J, et al. Reversal of drug sensitivity in multidrug-resistant cells by an MDR1 ribozyme. Cancer Res, 1994, 54: $1271 \sim 1275$

6 高振强, 高志萍, 张晓枇. 野生型 P53 基因对人肺㾂的生长抑制作用. 中国慢性病预防与控制, 1996,2: 66 69

7 高振强, 郑杰, 吴秉铑, 等. 苯并萠诱发人肺癌的裸鼠移植生物学研究. 中华病理学杂志, 1996,2: 106 107

8 Safa A R, Stern R K, Choi K, et al. Molecular basis of resistance to colchicine in multidrug-resistant human cells confers by Gly-185 by Bal \|185 substitution in Pgp. Proc Natl Acad Sci USA, 1990, 87: 7 225 7 229 


\section{1 材料与方法}

\section{$1.1 \mathrm{CO}_{2}$ 浓度控制}

1995 年 12 月至 1996 年 2 月, 用大面积塑料膜将生物圈二号内的热带雨林与沙漠区封 闭. 以大型空调通入新鲜空气, 使 $\mathrm{CO}_{2}$ 浓度逐步降低, 并维持在 $700 \sim 900 \mu \mathrm{mol} \cdot \mathrm{mol}^{-1}$ 和 300 $\sim 400 \mu \mathrm{mol} \cdot \mathrm{mol}^{-1}$ 阶段各 3 周, 使植物适应变化的 $\mathrm{CO}_{2}$ 浓度. 封闭前后温度、湿度、风速等均 以计算机监测系统控制, 因此气象因子较少发生变化(光照未受影响). 在 $\mathrm{CO}_{2}$ 浓度控制期间 进行光合作用的测定.

\section{2 处理用 $\mathrm{CO}_{2}$ 气体的获得}

在每个 $\mathrm{CO}_{2}$ 处理阶段, 白天选择适宜的时间 (太阳升起后生物圈二号内的 $\mathrm{CO}_{2}$ 浓度下降 很快, 约比早展低 $200 \sim 300 \mu \mathrm{mol} \cdot \mathrm{mol}^{-1}$ ), 用气原在实验地周围向密封塑料袋 (约 $20 \mathrm{~L}$ ) 充气. 这样采集的气体其温度、相对湿度、气体成分均少发生变化, 所得 $\mathrm{CO}_{2}$ 浓度高值时为 $(700 \pm$ 50) $\mu \mathrm{mol} \cdot \mathrm{mol}^{-1}$, 低值时为 $(350 \pm 20) \mu \mathrm{mol} \cdot \mathrm{mol}^{-1}$ (整个实验过程平均值), 基本代表加倍和目 前大气 $\mathrm{CO}_{2}$ 浓度. 处理用其他 $\mathrm{CO}_{2}$ 浓度如 500 和 $1000 \mu \mathrm{mol} \cdot \mathrm{mol}^{-1}$, 变化范围 $<10 \mu \mathrm{mol} \cdot$ $\mathrm{mol}^{-1}$.

\section{3 光反应曲线的测定}

光反应曲线指光合作用随光照强度变化而发生变化的曲线. 在不同的 $\mathrm{CO}_{2}$ 浓度处理下, 用美国拉哥公司制 LI-6400 光合作用系统 (已存程序) 测定. 测定时, 将上述气体通入仪器的 进气口. 这样, 仪器可在非常恒定的 $\mathrm{CO}_{2}$ 浓度 (一般一条曲线完成后 $\mathrm{CO}_{2}$ 变化 $<5 \mu \mathrm{mol}$. $\mathrm{mol}^{-1}$ ) 和其他环境参数下测定植物光合作用的变化. 主要环境参数为: 热带雨林, 大气温度 $(28 \pm 2)^{\mathrm{C}} \mathrm{C}$, 叶面温度 $(29 \pm 2)^{\mathrm{C}} \mathrm{C}$, 相对湿度 $80 \% \pm 5 \%$; 沙漠, 大气温度 $(23 \pm 3)^{\mathrm{C}} \mathrm{C}$, 叶面温度 $(24 \pm 2){ }^{\circ} \mathrm{C}$, 相对湿度 $40 \% \pm 10 \%$ 。

\section{2 结果与讨论}

\section{1 光反应曲线形状}

一些研究认为 ${ }^{[6]}, \mathrm{CO}_{2}$ 浓度升高引起光反应曲线开始时的陡度变陡, 本研究发现同样的现 象, 其中雨林植物尤为明显 (图 1). 花叶万年青 (Dieffenbachia $\mathrm{sp}$ ) 等 3 种雨林植物在 $\mathrm{CO}_{2}$ 浓 度 $700 \mu \mathrm{mol} \cdot \mathrm{mol}^{-1}$ 时起初 $\left(10 \sim 350 \mu \mathrm{mol} \cdot \mathrm{m}^{-2} \cdot \mathrm{s}^{-1}\right)$ 的曲线几乎与 $y$ 轴平行; 而在 $350 \mu \mathrm{mol}$. $\mathrm{mol}^{-1}$ 时则约成 $45^{\circ}$ 角, 沙漠 $\mathrm{C}_{3}$ 植物初始反应曲线也在 $\mathrm{CO}_{2}$ 升高时变陡, 但不如雨林植物明 显; $\mathrm{C}_{4}$ 草本植物大乘 (Panicum maximum) 几乎不变. 所测雨林植物中, 花叶万年青为林下阔 叶草本植物, 牵牛 (Ipomoea $\mathrm{sp}$ ) 为攀缘植物, 蝶豆 (Clitoria racemosa) 为亚冠层木本植物. 它 们在低光时的光合速率升高较快, 在高 $\mathrm{CO}_{2}$ 时表现更明显, 与这类植物长期适应弱光环境有 关. 除了初始曲线陡度的改变外, 5 种植物 $\left(\mathrm{C}_{4}\right.$ 植物除外) 都表现出在高 $\mathrm{CO}_{2}$ 下光反应曲线弯 度增大, 即在光饱和点以后高 $\mathrm{CO}_{2}$ 下的光合速率明显超出背景 $\mathrm{CO}_{2}$ 下的值. 其中沙漠木本植 物粉蓝烟草 (Nicotiana glauca) 曲线在高 $\mathrm{CO}_{2}\left(700\right.$ 和 $1000 \mu \mathrm{mol} \cdot \mathrm{mol}^{-1}$ )下为开放型, 无明显 的光饱和点; 而在 350 和 $500 \mu \mathrm{mol} \cdot \mathrm{mol}^{-1}$ 时光饱和点非常突出. 该植物为多乳汁植物, 对水分 的利用效率很高, 在高 $\mathrm{CO}_{2}$ 下表现出异常高的光合作用. 相反, $\mathrm{C}_{4}$ 植物大㯟在 $\mathrm{CO}_{2} 700 \mu \mathrm{mol}$. $\mathrm{mol}^{-1}$ 时光饱和点以后的光合速率低于 350 和 $500 \mu \mathrm{mol} \cdot \mathrm{mol}^{-1}$ 状态下光合速率. Hand 等人 ${ }^{[6]}$ 
出漠植物
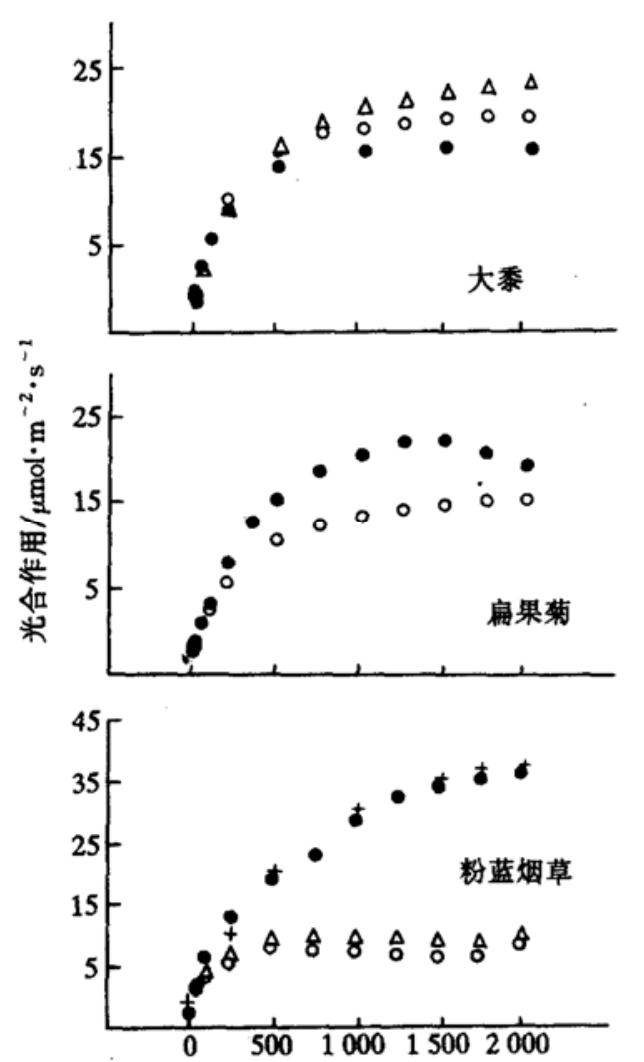

雨林植物
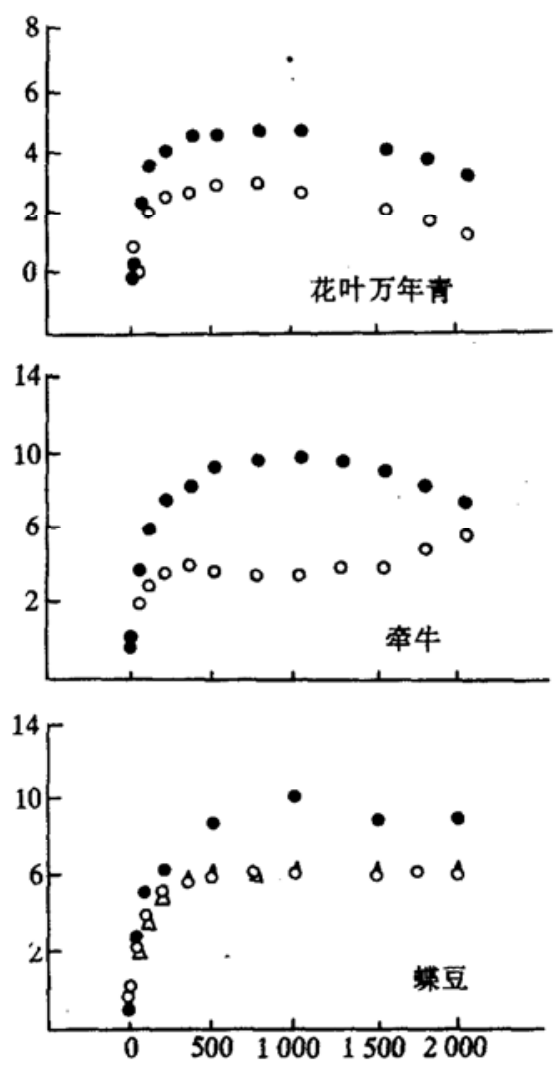

光照强度 $/ \mu \mathrm{mol} \cdot \mathrm{m}^{-2} \cdot \mathrm{s}^{-1}$

图 1 生物圈二号内沙漠植物与雨林植物光合作用在不同 $\mathrm{CO}_{2}$ 浓度下随光照强度所 发生的变化曲线

$\mathrm{CO}_{2}$ 浓度 $/ \mu \mathrm{mol} \cdot \mathrm{mol}^{-1}: \mathrm{O}-350, \Delta-500,-700,+-1000$

报道 $\mathrm{C}_{4}$ 植物光合速率随 $\mathrm{CO}_{2}$ 浓度升高不发生变化甚至呈下降趋势, 本研究可证实这一点.

\section{2 光补偿点与饱和点}

雨林植物中除蝶豆光补偿点在 $\mathrm{CO}_{2}$ 浓度 $700 \mu \mathrm{mol} \cdot \mathrm{mol}^{-1}$ 时为 $50 \mu \mathrm{mol} \cdot \mathrm{m}^{-2} \cdot \mathrm{s}^{-1}$, 表现为 升高外, 其他两种植物未发生变化, 光补偿点均为 $10 \mu \mathrm{mol} \cdot \mathrm{m}^{-2} \cdot \mathrm{s}^{-1}$ (表 1). 沙漠植物无论 $\mathrm{C}_{3}$ 还是 $\mathrm{C}_{4}$ 植物的两种 $\mathrm{CO}_{2}$ 浓度下的光补偿点不变, 为 $50 \mu \mathrm{mol} \cdot \mathrm{m}^{-2} \cdot \mathrm{s}^{-1}$. 虽然蝶豆在光照强度 $10 \mu \mathrm{mol} \cdot \mathrm{m}^{-2} \cdot \mathrm{s}^{-1}$ 时发生光合作用, 然其值仅为 $0.041 \mu \mathrm{mol} \mathrm{CO} \cdot \mathrm{m}^{-2} \cdot \mathrm{s}^{-1}$, 接近于 0 , 故可认为 其光补偿点应在 $50 \mu \mathrm{mol} \cdot \mathrm{m}^{-2} \cdot \mathrm{s}^{-1}$. 这样看来所有植物的光补偿点没有受到高 $\mathrm{CO}_{2}$ 浓度的影 响.

$\mathrm{C}_{3}$ 植物的光饱和点在高 $\mathrm{CO}_{2}$ 浓度下表现升高, 雨林植物平均升高 $220 \mu \mathrm{mol} \cdot \mathrm{m}^{-2} \cdot \mathrm{s}^{-1}$, 沙 漠 $\mathrm{C}_{3}$ 植物 $250 \mu \mathrm{mol} \cdot \mathrm{m}^{-2} \cdot \mathrm{s}^{-1}$; 其中粉蓝烟草在高 $\mathrm{CO}_{2}$ 下并不表现明显的光饱和现象. $\mathrm{C}_{4}$ 植 物的光饱和点仍不变, 为 $1000 \mu \mathrm{mol} \cdot \mathrm{m}^{-2} \cdot \mathrm{s}^{-1}$. 沙漠植物的光补偿点和饱和点均高于雨林植 物 (表 1), 与其长期适应沙漠强光环境有关; 相反, 雨林植物尤其是林冠下层植物长期生长在 弱光环境下, 在较弱的光照下也能进行光合作用. 
表 1 生物圈二号内热带雨林及沙漠植物在目前 $\mathrm{CO}_{2}\left(350 \mu \mathrm{mol} \cdot \mathrm{mol}^{-1}\right)$ 和加倍 $\mathrm{CO}_{2}\left(700 \mu \mathrm{mol} \cdot \mathrm{mol}^{-1}\right)$ 浓度下光补偿点、饱和点、最大表观光能利用率和最大光合速率的比较

\begin{tabular}{|c|c|c|c|c|c|c|c|c|}
\hline \multirow{3}{*}{ 植物名称 } & \multicolumn{2}{|c|}{ 光补偿点 } & \multicolumn{2}{|c|}{ 光饱和点 } & \multirow{2}{*}{\multicolumn{2}{|c|}{$\begin{array}{c}\text { 最大表观光能利用效率 } \\
/ \mu \mathrm{mol} \cdot \mathrm{m}^{-2} \cdot \mathrm{s}^{-1}\end{array}$}} & \multirow{2}{*}{\multicolumn{2}{|c|}{$\begin{array}{l}\text { 最大光合速率 } \\
/ \mathrm{mmol}^{\prime} \mathrm{mol}^{-1}\end{array}$}} \\
\hline & \multicolumn{4}{|c|}{$/ \mu \mathrm{mol} \cdot \mathrm{m}^{-2} \cdot \mathrm{s}^{-1}$} & & & & \\
\hline & 350 & 700 & 350 & 700 & 350 & 700 & 350 & 700 \\
\hline \multicolumn{9}{|c|}{ 雨林植物 } \\
\hline 䗲豆 & 10 & 50 & 500 & 1000 & 34.42 & 43.97 & 5.78 & 10.00 \\
\hline 花叶万年青 & 10 & $\quad 10$ & 500 & 500 & 16.06 & 41.22 & 2.94 & 4.59 \\
\hline 牵牛 & 10 & 10 & 350 & 500 & 27.75 & 56.93 & 4.02 & 9.43 \\
\hline 平均 & 10 & 23 & 450 & 670 & 26.07 & 47.37 & 4.24 & 8.00 \\
\hline \multicolumn{9}{|c|}{ 沙漠植物 } \\
\hline 扁果菊 & 50 & 50 & 1000 & 1250 & 21.37 & 36.04 & 13.17 & 22.13 \\
\hline 粉蓝烟草 & 50 & 50 & 500 & - & 26.97 & 49.74 & 7.92 & 36.28 \\
\hline 大黍 & 50 & 50 & 1000 & 1000 & 54.42 & 49.27 & 17.96 & 15.45 \\
\hline 平均 & 50 & 50 & 830 & 1120 & 34.25 & 45.01 & 13.02 & 24.62 \\
\hline
\end{tabular}

一些研究认为 ${ }^{[7]}, \mathrm{C}_{3}$ 植物在高 $\mathrm{CO}_{2}$ 浓度短期反应中, 减小光饱和点; 而 $\mathrm{C}_{4}$ 植物不变. 本 研究结果表明长期生长在很高 $\mathrm{CO}_{2}$ 环境下的植物, $\mathrm{C}_{3}$ 植物光补偿点基本不变, 但光饱和点提 高; $\mathrm{C}_{4}$ 植物不变. 说明 $\mathrm{C}_{3}$ 植物为消化增加的 $\mathrm{CO}_{2}$, 植物光合作用系统功能增强, 对光能强度 的要求相应提高.

\section{3 最大表现光能利用效率与最大光合速率}

最大表观光能利用效率是植物每获取 $1 \mathrm{~mol}$ 光能所能同化 $\mathrm{CO}_{2}$ 的 $\mathrm{mol}$ 数量, 以 $\Phi_{\mathrm{m}, \text { app }}$ 表 示. 因未扣除光能在叶面上的反射和透射, 以实际辐射光能为准, 且以光反应曲线补偿点以上 最初几个点计算, 故称最大表观光能利用效率 ${ }^{[7]}$. 最大光合速率 $\left(A_{\max }\right)$ 指植物达到光饱和点 时的光合强度. 这两项指标的改变能够说明在高 $\mathrm{CO}_{2}$ 环境下植物内部消耗 $\mathrm{CO}_{2}$ 与传输、储藏 碳水化合物能力变化, 同时反应光合作用关键酶 (如 RuBP 羧化酶) 含量与活性的改变, 还与 $\mathrm{CO}_{2}$ 的传导及 $\mathrm{CO}_{2}$ 浓缩机制有关. 在高 $\mathrm{CO}_{2}$ 浓度下 $\Phi_{\mathrm{m}, \text { app }}$ 及 $A_{\max }$ 变化机理比较复杂, 需专 题深入研究. 生物圈二号内雨林植物的 $\Phi_{\mathrm{m}, \mathrm{app}}$ 从 $\mathrm{CO}_{2} 350 \mu \mathrm{mol} \cdot \mathrm{mol}^{-1}$ 时的 $26.07 \mathrm{mmol} \mathrm{CO} /$ $\mathrm{mol}$ 光, 上升到 $700 \mu \mathrm{mol} \cdot \mathrm{mol}^{-1}$ 时的 $47.37 \mathrm{mmol} \mathrm{CO} / \mathrm{mol}$ 光, 升高 $81 \%$; 沙漠 $\mathrm{C}_{3}$ 植物从 24.17 提高到 $42.89 \mathrm{mmol} \mathrm{CO} / 2 / \mathrm{mol}$ 光, 升高 $77 \% . A_{\max }$, 雨林植物从 4.24 上升到 $8.00 \mu \mathrm{mol}$ $\mathrm{CO}_{2} \cdot \mathrm{m}^{-2} \cdot \mathrm{s}^{-1}$, 提高了 $88 \%$; 沙漠 $\mathrm{C}_{3}$ 模物从 10.92 上升到 $18.64 \mu \mathrm{mol} \mathrm{CO} 2 \cdot \mathrm{m}^{-2} \cdot \mathrm{s}^{-1}$, 提高 $71 \%$. 而 $\mathrm{C}_{4}$ 植物大秀 $\Phi_{\mathrm{m}}$, app 从 54.42 下降到 $49.27 \mathrm{mmol} \mathrm{CO} / \mathrm{mol}$ 光; $A_{\max }$ 从 17.96 下降到 $15.45 \mu \mathrm{mol} \mathrm{CO} \mathrm{CO}_{2} \cdot \mathrm{m}^{-2} \cdot \mathrm{s}^{-1}$, 分别降低 $10 \%$ 和 $14 \%$. 平均来看, 生物圈二号 $\mathrm{C}_{3}$ 植物 $\Phi_{\mathrm{m}, \text { app }}$ 提高 $79 \%, A_{\max }$ 提高 $80 \%$. 有人预测 $\mathrm{C}_{3}$ 植物光合作用在 $\mathrm{CO}_{2}$ 加倍后平均升高 $10 \% \sim 50 \%{ }^{[3]}$, 本 研究 $\mathrm{C}_{3}$ 植物比其高几十个百分点, 可能与生物圈二号的植物长期生长在很高的 $\mathrm{CO}_{2}$ 环境有 关. $\mathrm{C}_{4}$ 植物光合速率的变化与有关报道基本一致 ${ }^{[4]}$.

由于实验条件限制, 本研究未能在野外自然状态下测定热带雨林与沙漠植物在不同 $\mathrm{CO}_{2}$ 下光合能力的变化并与生物圈二号同种植物比较, 有待于深入的探讨.

\section{3. 结论}

生物圈二号长期生长在很高 $\mathrm{CO}_{2}$ 浓度 $\left(>2200 \mu \mathrm{mol} \cdot \mathrm{mol}^{-1}\right)$ 下的 $\mathrm{C}_{3}$ 植物在高 $\mathrm{CO}_{2}(700$ $\left.\mu \mathrm{mol} \cdot \mathrm{mol}^{-1}\right)$ 浓度比目前 $\mathrm{CO}_{2}$ 浓度 $\left(350 \mu \mathrm{mol} \cdot \mathrm{mol}^{-1}\right)$ 最初时的光反应曲线变陡, 光补偿点不 
【研究简报】

\title{
水稻条纹叶枯病毒基因组含 vRNA2 ORF 片段 的克隆、序列分析及其在原核中的表达
}

\author{
王晓红叶寅王苏燕田波
}

(中国科学院微生物研究所病蒌研究室, 北京 100080)

\section{关镜词水稻条纹叶枯病毒 vRNA2 ORF 序列测定 高效表达}

水稻条纹叶枯病毒 (rice stripe virus, RSV) 是柔丝病毒组的典型代表, 其基因组由 4 种 ss-RNA及相应低含量的 4 种 dsRNA 组成, 其中, RNA1 为负链性质, 编码 RNA 多聚酶; RNA2 $\sim 4$ 均为双义编码性质 (ambisense-coding strategy) ${ }^{[1]}$. 为研究该病毒 RNA 非编码区等调控元 件在病毒基因组双义表达过程中的功能, 采用反转录-聚合酶链式反应方法(RT-PCR), 扩增出 覆盖 RSV RNA2 5'末端非编码区、vRNA2OrFT 区、基因间非编码区及 vcRNA2 ORF 部分区 域的 REPI 片段 (1 159bp). 将此扩增产物克隆于载体 pGEM-7Zf $(+)$ 的 Sma I 位点上并进行 了核苷酸序列测定. 结果表明, 中国分离物与日本分离物的 REPI 片段具极高的序列同源性. 将 REPI 片段克隆到原核高效表达载体 pJW2 的 $\mathrm{P}_{\mathrm{R}} \mathrm{P}_{\mathrm{L}}$ 启动子下游, 经温度诱导, 获得了高效

变、光饱和点提高; 最大光能利用效率最大光合速率分别提高 $79 \%$ 和 $80 \%$. 而 $\mathrm{C}_{4}$ 植物光反应 曲线形状基本不变, 最大光能利用效率和最大光合速率下降 $10 \%$ 和 $14 \%$, 证明了在高 $\mathrm{CO}_{2}$ 浓 度下生长的 $\mathrm{C}_{3}$ 植物光合能力提高, 而 $\mathrm{C}_{4}$ 植物并不提高, 反略有下降.

致谢 本研究主要经费来自世界银行贷款中国生态系统研究网络 (CERN-TOR-sup.02) 项目, 部分资助来自美国哥伦比亚大学生物圈二号研究中心.

\section{参考文献}

1 Gaudillere J P, Mousseau M. Short term effect of $\mathrm{CO}_{2}$ enrichment on leaf development and gas exchange of young poplars (Populus euramericana CV I 214). Acta Oecologica, 1989, 10: 95 105

2 Acock B, Reddy V R, Hodges H F, et al. Photosynthetic response of soybean canopies to full-season carbon dioxide environment. Agron J, 1985, 77: 942 947

3 Idso K E, Idso S B. Plant responses to atmospheric $\mathrm{CO}_{2}$ enrichment in the face of environmental constraints: a review of the past 10 years' research. Agriculture and Forest Meteorology, 1994, 69: 153 203

4 Arp W J, Drake B G, Pockman W T, et al. Interactions between $\mathrm{C}_{3}$ and $\mathrm{C}_{4}$ salt marsh plant species during four years exposure to elevated atmorpheric $\mathrm{CO}_{2}$. Vegetatio, 1993, 104/105: 133 143

5 Habash D Z, Paul M J, Parry M A J, et al. Increased capacity for photosynthesis in wheat grown at elevated $\mathrm{CO}_{2}$ : the relationship between electron transport and carbon metabolism. Planta, 1995, 197: 482 489

6 Hand D W, Witson J W, Acock B. Effects of light and $\mathrm{CO}_{2}$ on net photosynthetic rates of stands of Aubergine and Amaranthus. Annals of Botany, 1993, 209 216

7 Long S P, Baker N R, Raines C A. Analyzing the response of photosynthetic $\mathrm{CO}_{2}$ assimilation to long-term elevation of atmospheric $\mathrm{CO}_{2}$ concentration. Vegetatio, 1993, 104/105: 33 45 